\title{
The Influence of Temporal Choice, Correlation, and Sample Size on Income Convergence $^{+}$
}

\author{
Shahdad Naghshpour*
}

\begin{abstract}
. $\beta$-convergence is determined by the sign of the slope of the income growth line. The conclusion of significance, hence convergence or divergence, is affected by the temporal choice. Changes in the starting and ending periods influence the conclusion of convergence, lack of significance, or divergence. The customary $t$-test for significance of slope is influenced by correlation between the base year and the growth rate over the period of study as well as the sample size. To separate the two contributing factors, the $t$-test is formulated as a function of the correlation coefficient.
\end{abstract}

Key Words: income convergence, sample size, $\beta$-convergence, $\sigma$ - convergence.

JEL Classifications: R11, D31, O51

\section{INTRODUCTION}

Studies of income inequality date back to Hume (1752) and Smith (1776). Some more recent empirical works include: Amos (1986), Ram (1992), Rowley, Redman, and Angle (1991), and Levernier, Rickman, and Partridge (1995). Levy and Murnane (1992) provide a summary of some of the diverse methods used to study income inequality. Following Barro and Sala-i-Martin (1991), current studies focus on income convergence. Since the neoclassical growth theory and the endogenous growth theory predict different convergence outcomes (Howitt, 2000), the theoretical debates of Smith, Hume, and Myrdal (1957), Solow (1956), and Romer (1989) have given way to the empirical studies of convergence, which find evidence in support of both the convergence and the divergence of income. This is evident in the works of Amos (1991), Maxwell and Hite (1992), Carlino and Mills (1996), Eff (1999), Bernat (2001), Latzko (2001), Nissan and Carter (2001), and Santopietro (2002). It is important that the evidence proclaimed by the empirical study is based on the actual convergence or divergence of income inequality and not on factors unrelated to the convergence issue. The choice of method should not influence the outcome. Lack of robustness is a problem in convergence studies, regardless of the method (BenDavid, 1998). The present study demonstrates that the convergence, divergence, or lack of significant relation is influenced by temporal choice, due to the correlation associated with pairs of beginning and ending periods and the number of observations.

Although Bernat (2001) argues that there is only one type of convergence, empirically, three convergence concepts have been heralded. They are $\beta$-convergence (Baumol, 1986), $\sigma$ convergence (Barro and Sala-i- Martin, 1991), and stochastic convergence (Bernard, 1991).

\footnotetext{
${ }^{+}$I thank Professor Judith Stallmann for reviewing this paper and the three anonymous reviewers for excellent comments especially on spatial correlation coefficient. Any remaining errors are solely mine.

* Professor of Economics at University of Southern Mississippi-Gulf Coast.

Contact Information: The University of Southern Mississippi Gulf Coast, 730 East Beach Boulevard, Long Beach, MS 39560, USA. E-mail: s.naghshpour@usm.edu.

(C) Southern Regional Science Association 2010.

ISSN 1553-0892

SRSA, 1601 University Avenue, PO Box 6025, Morgantown, West Virginia 26506-6025, USA
} 
Stochastic convergence occurs when permanent shocks to the national economy are associated with permanent shocks to the regional economies, in the sense of unit roots and cointegration described by Engle and Granger (1987). $\sigma$-convergence is concerned with the change in the distance or dispersion of incomes among the economies. If the variance among the incomes declines over time, their distances decline. A declining coefficient of variation (standard deviation divided by mean) signifies $\sigma$-convergence, which is verified by a negative trend line slope. A positive slope indicates $\sigma$-divergence. $\beta$-convergence addresses the change in the position of the economies or their mobility. It means that poorer economies grow faster than richer economies. Obtaining a statistically significant negative slope for the regression of the average growth rate of per capita income over a period on the base year per capita income is evidence of $\beta$-convergence. A statistically significant positive slope indicates $\beta$-divergence.

This study is concerned with the use of regression to determine $\beta$-convergence and $\sigma$ convergence. The use of regression analysis for determining income convergence has been criticized by Friedman (1992) and Quah (1993). While this paper acknowledges their contribution, it addresses a different issue. The problem is more relevant for $\beta$-convergence than for $\sigma$-convergence, because there are more choices for the beginning and ending periods in the studies using $\beta$-convergence methods, as is explained later. Another important factor is the correlation between adjacent units of measurement, especially when county per capita income is used (Rey, 2001). This lack of independence of neighboring counties has been the focus of spatial econometrics (Anselin, 1988; Fingleton, 1999). Rey (2001) addresses the issue and provides an alternative method using Markov chains, following Quah (1993). In an extreme case of perfect spatial correlation a sample size of one would suffice. When there is no spatial correlation the "effective sample size" is actually the number of observations (Griffith, 2007). ${ }^{1}$

\section{BACKGROUND}

\subsection{The Problem of Using Regression to Determine Convergence}

When the pattern of convergence or divergence is stable, any segment of the data could be used to determine whether income converges or diverges. Similarly, if convergence patterns are geographic-invariant the choice of location becomes irrelevant. Finally, if convergence is not affected by the level of aggregation, then the size of the unit, county versus state, would not matter.

By definition, only one regression is sufficient for determining $\sigma$-convergence for a given group of economic entities, such as a group of counties, states, regions, or nations. Empirical studies of $\sigma$-convergence regress coefficients of variations for geographical units on the time variable (Carlino and Mills, 1996). A negative slope indicates convergence, while a positive slope indicates divergence. In both cases, the conclusion pivots on statistical significance. The sample for studies of $\sigma$-convergence is short, between 20 to 50 observations. On the other hand, the sample for cross-section studies may exceed thousands. For example, a study of counties in the United States involves 3,075 counties, while a study of BEA regions only has eight regions. The claim of this study is that the difference in the number of observations influences the conclusion, other things equal.

\footnotetext{
${ }^{1}$ This was pointed out by an anonymous reviewer to whom I am grateful.

(c) Southern Regional Science Association 2009.
} 
For $\beta$-convergence, the average growth rate over a period is regressed on the income of the initial or the base year. For any $T$ periods there are $N=(T ! / 2 !(T-2) !)=T(T-1) / 2$ possible combinations of growth rates. Understandably, executing all possible regressions is formidable. Consequently, in practice, relatively few regressions are conducted. Carlino and Mills (1996) perform one regression for the entire period using the eight BEA regions from 1929 to 1990. Morrill (2000) uses two census years, 1970 and 1990. Usually, the most recent data and the oldest available data are utilized. This is acceptable if the relation has temporal robustness and if the relation is stable.

The evidence points to instability. Appendix Table A1 presents the correlation coefficients for the pairs of per capita income of years from 1969 through 2001 for the eight major regions developed by the U.S. Bureau of Economic Analysis (henceforth, BEA regions). The range is from $(-.893)$ to $(+.774)$. In most cases, the changes are gradual, but there are exceptions. For example, the correlation between 1969 and 1970 (-.6905) is not statistically significant, but that of 1969 and 1971 (-.832) is significant. While the latter indicates convergence of incomes, the former does not. As will be demonstrated later, significance of the correlation coefficient is the same as significance of the slope of regression line, indicating convergence or divergence depending on whether the correlation coefficient is negative or positive, respectively. There is evidence of more drastic changes. For example, for the state data (not shown) the correlation between 1987 and 1989 is positive and significant (divergence) and between 1988 and 1990 is negative and significant (convergence). Barro and Sala-i-Martin (1992) also report evidence of changes from convergence to divergence. Frequent changes in the direction or lack of robustness of the outcome necessitate frequent surveillance. A preferred alternative is to consider all the possible combinations of base years and end years (Eff, 1999), a very formidable task with the features available in existing statistical analysis packages.

Eff (1999) performs all 378 possible regressions for the period 1969 to 1996, using per capita income of the 3,076 counties of the lower 48 U.S. states. He obtains two positive slopes (divergence), six insignificant slopes (inconclusive), and 370 negative slopes (convergence). This is neither a coincidence nor a reflection of overwhelming evidence in support of convergence. The outcome depends on both the correlation and the number of observations.

The point goes beyond the "regression to the mean” problem (Quah, 1993; Hart 1995). In a response to this problem Barro and Sala-i-Martin (2004, p. 51) state:

The observation that heights in a family tend to regress toward the mean across generations (a property analogous to our convergence concept for per capita income) does not imply that the dispersion of heights across the full population (a measure that parallels the dispersion of per capita income across economies) tends to narrow over time.

Thus, the use of more homogenous groups of economies such as the U.S. states or regions would be permissible (Barro and Sala-i-Martin, 2004). The present paper shows that regardless of the valid points that Quah (1993) makes and equally valid counterpoints of Barro and Sala-i-Martin (2004) there are concerns about the arbitrary choice of the year and hence the length of the study period. The present study demonstrates the importance of the temporal dimension in addition to the spatial dimension, which has been demonstrated by Rey (2001), among others. To make sure that there is no doubt about temporal influence, all three commonly used groups of "regions, states, and countries” are utilized.

(c) Southern Regional Science Association 2009. 


\subsection{The Relationship between Test Statistics, Sample Size, and the Correlation Coefficient}

The customary method of testing the significance of individual slopes is through $t$ statistics, which is expressed in terms of the estimated slope and its standard error. There are alternative presentations of this test, which provide greater insight on the issue at hand. One alternative for testing the hypothesis of zero slope involves both the correlation coefficient and sample size. The $t$-statistics for testing the significance of slope is given by:

(1a) $t=\hat{\beta}_{1} /\left(\sqrt{S S E /(N-2)} / \sqrt{S_{X X}}\right)=\left(\sqrt{N-2} \sqrt{S_{X X}} \hat{\beta}_{1}\right) / \sqrt{S S E}$

where $N$ is the number of observations in the sample $\hat{\beta}_{1}$ is the estimated slope of the regression line, $S_{X X}$ is the sum of the squares of deviation of the independent variables from their means, and SSE is the sum of the squares of error. Substituting for the estimated dependent value, $\hat{Y}$, in $S S E$ and rearranging the formula yields the following:

$$
\begin{aligned}
& \text { (1b) } S S E=\Sigma(Y-\hat{Y})^{2}=\Sigma\left(Y-\hat{\beta}_{0}-\hat{\beta}_{1} X\right)^{2}=\Sigma\left[Y-\left(\bar{Y}-\hat{\beta}_{1} \bar{X}\right)-\hat{\beta}_{1} X\right]^{2}, \\
& \text { (1c) } S S E=\Sigma\left[(Y-\hat{Y})-\hat{\beta}_{1}(X-\bar{X})\right]^{2}=\Sigma(Y-\hat{Y})^{2}-\hat{\beta}_{1}^{2} \Sigma(X-\bar{X})^{2} \\
& \text { (1d) } S S E=\Sigma(Y-\hat{Y})^{2}-\left\{[\Sigma(X-\bar{X})(Y-\hat{Y})]^{2} / \Sigma(X-\bar{X})^{2}\right\} \\
& \text { (1e) } S S E=S_{Y Y}-\left(S_{X Y}^{2} / S_{X X}\right)
\end{aligned}
$$

where $S_{Y Y}$ is the sum of the squares of deviation of the dependent values from their mean, and $S_{X Y}$ is the sum of the cross product of deviations of $X$ s from their mean times the deviations of $Y \mathrm{~s}$ from their mean. Substituting $S S E$ in $t$-statistics yields:

(2a) $t=\frac{\sqrt{N-2} \sqrt{S_{X X}} \hat{\beta}_{1}}{\sqrt{S S E}}=\frac{\sqrt{N-2} \sqrt{S_{X X}}\left(S_{X Y} / S_{X X}\right)}{\sqrt{\left(S_{Y Y} S_{X X}-S_{X Y}^{2}\right) / S_{X X}}}=\frac{S_{X Y} \sqrt{N-2}}{\sqrt{S_{X X} S_{Y Y}-S_{X Y}^{2}}}$

(2b) $t=\frac{\sqrt{N-2}}{\sqrt{\left(S_{X X} S_{Y Y} / S_{X Y}^{2}\right)-1}}=\frac{\sqrt{N-2}}{\sqrt{\left(1 / \hat{\rho}^{2}\right)-1}}$

where $\hat{\rho}$ is the estimated correlation coefficient between the dependent and independent variables. This statistic is only valid for testing the hypothesis that $\beta_{1}=0$, which is the relevant hypothesis for $\beta$-convergence. According to Equation (2), for a given correlation coefficient, the larger the number of observations, the larger the $t$-statistics, and hence the greater the chance of rejecting the null hypothesis. Similarly, for a given sample size, the larger the correlation coefficients, the larger are the $t$-statistics and, hence, the greater the chance of rejecting null hypotheses.

(C) Southern Regional Science Association 2009. 
This derivation is not new. It has been used in correlation analysis as far back as David (1938), who provides a table of levels of significance for the correlation coefficient. To that end, Equation (2) can be rearranged in terms of the correlation coefficient, which can be used to test the significance of the model and the slope. In the result, $\hat{\rho}$ is replaced by $R$ to indicate that this is a test similar to $t$ and $F$ :

(3) $R=\sqrt{t^{2} /\left(N-2+t^{2}\right)}, \quad$ for $N \geq 3$

In this form, after selecting a level of significance, the value of $t$ becomes a constant, which leaves $N$ as the only variable. For any given data, testing the significance of the estimated correlation coefficient is identical to testing the significance of the slope. For example, for $N=3$ in a simple regression, the $t$ value at 5 percent significance is 12.076 , which results in $R=.9969$. For a sample size of three, the hypothesis of zero slope is rejected if the calculated $t$-statistic for the estimated slope is greater than 12.06, or alternatively, if the estimated correlation coefficient between the dependent and independent variables is greater than .9969 in absolute value. Simple calculations, or consultation with David (1938), provide the cutoff points for significant values of $R$, some of which are depicted in Table 1 . The table also provides the observed correlation coefficient for the eight BEA regions, the lower 48 states, and the 3,075 counties in the lower 48 states in the U.S. for the years 1969 to 2001. Note that the $t$-values in Equation (3) are the tabulated values based on $(N-2)$ degrees of freedom.

As indicated in Table 1, for a given level of correlation between the dependent variable and independent variable, different sample sizes may indicate a different outcome. The smaller the number of observations, the smaller is the number of statistically significant results. This is important because in recent years the emphasis has been on finding evidence in support of neoclassical growth theory or endogenous growth theory using convergence criteria such as $\beta$ convergence. The problem is that the evidence not only depends on the correlation, but also depends on the sample size, as indicated by Equation (3). In empirical studies, such as the study of convergence for a given state or region, both correlations and sample sizes differ; consequently, in studies with smaller sample sizes, the correlation must be stronger than that of the studies with larger sample size to obtain the same results. Although the correlation for years 1969 and 2001 is higher for regions than it is for states or all counties, the test for the first lacks statistical significance, while the other two are statistically significant. The result is true regardless of any other factor, except for the correlation coefficient.

There are some practical advantages to using the correlation-based statistics $(R)$. For the years 1969 to 2001, there are 33 years selected two at a time, creating 528 possible regressions for each of the 48 states, or over 25,344 regressions. Since the existing statistical software is

TABLE 1. Cutoff and Observed Correlation Coefficients between the Growth Rate of Per Capita Income from 1969 to 2001 and the Level of 1969 Per Capita Income

\begin{tabular}{llrrl}
\hline \hline U.S. Areal Unit & Cutoff for $R$ & Observed $R$ & Conclusion \\
\hline Regions & $N=8$ & .7067 & .5360 & Not significant \\
States & $N=48$ & .2816 & .3434 & Significant \\
Counties & $N=3075$ & .0353 & .3792 & Significant \\
\hline \hline
\end{tabular}

(C) Southern Regional Science Association 2009. 
designed for individual regression analysis, the collection and tabulation of the slopes becomes tedious and cumbersome. Spreadsheets, on the other hand, are suitable for creating limited numbers of "formulas" and copying them to replicate the same procedure for similarly formatted data. Proper use of relative and absolute referencing makes the task less formidable. Spreadsheets can calculate the correlation coefficient as easily as the regression slope. However, the correlation coefficient and Equation (3) can automate the decision rule. Later, in Table 6 in the next section, the results of convergence tests for all 48 lower states over the 33 years are reported.

\section{EMPIRICAL STUDY}

The Bureau of Economic Analysis (BEA) provides the Regional Economic Information System (REIS), which includes per capita income annually for each BEA region, state, and county. Tables 2 through 4 display the results for 528 convergence tests for the eight regions, 48 lower states, and 3,075 counties in those states, respectively.

As expected, the results for the eight regions have more non-significant cases (Table 2) that are indicated by "0", as well as fewer significant cases that are indicated by "C" for convergence or " $\mathrm{D}$ " for divergence. Table 4, which represents the results for 3,075 counties, is dominated by Cs.

Table 5 displays the counts of negative slopes, positive slopes, convergence, divergence, non-significant slopes, relative frequency of convergence, and relative frequency of divergence for counties in each state. It also reports the results for the eight BEA regions, the 48 lower states, and the 3,075 counties. Note that the sums for the number of negatives and positives, as well as the sums for Cs, Ds, and 0s for each row, add to 528 cases. For each state, the relative frequency of convergence and divergence is calculated by dividing the number of significant negative and significant positive slopes by the observed number of negative and positive slopes. For example, of the 528 regression slopes for counties in Alabama, 61 have positive slopes and

TABLE 2. Convergence and Divergence for Eight BEA Regions by Year

\begin{tabular}{|c|c|c|c|c|c|c|c|c|c|c|c|c|c|c|c|c|}
\hline & 69 & 70 & 71 & 72 & 73 & 74 & 75 & 76 & 77 & 78 & 79 & 80 & 81 & 82 & 83 & 84 \\
\hline 69 & 0 & $\mathrm{C}$ & $\mathrm{C}$ & C & C & C & $\mathrm{C}$ & C & C & $\mathrm{C}$ & $\mathrm{C}$ & C & C & $\mathrm{C}$ & $\mathrm{C}$ & C \\
\hline 70 & & $\mathrm{C}$ & C & C & C & C & C & C & C & C & C & C & C & C & C & C \\
\hline 71 & & & C & 0 & C & C & C & C & C & C & C & C & C & C & C & 0 \\
\hline 72 & & & & 0 & C & 0 & 0 & 0 & 0 & 0 & 0 & 0 & 0 & 0 & 0 & 0 \\
\hline 73 & & & & & 0 & 0 & 0 & 0 & 0 & 0 & 0 & 0 & 0 & 0 & 0 & 0 \\
\hline 74 & & & & & & 0 & 0 & 0 & 0 & 0 & 0 & 0 & 0 & 0 & 0 & 0 \\
\hline 75 & & & & & & & 0 & 0 & 0 & 0 & 0 & 0 & 0 & 0 & 0 & 0 \\
\hline 76 & & & & & & & & 0 & 0 & 0 & 0 & 0 & 0 & 0 & 0 & 0 \\
\hline 77 & & & & & & & & & 0 & 0 & 0 & 0 & 0 & 0 & 0 & 0 \\
\hline 78 & & & & & & & & & & 0 & 0 & 0 & 0 & 0 & 0 & 0 \\
\hline 79 & & & & & & & & & & & 0 & 0 & 0 & 0 & 0 & 0 \\
\hline 80 & & & & & & & & & & & & 0 & 0 & 0 & 0 & 0 \\
\hline 81 & & & & & & & & & & & & & 0 & 0 & 0 & 0 \\
\hline 82 & & & & & & & & & & & & & & 0 & 0 & 0 \\
\hline 83 & & & & & & & & & & & & & & & 0 & 0 \\
\hline 84 & & & & & & & & & & & & & & & & 0 \\
\hline
\end{tabular}

(c) Southern Regional Science Association 2009. 
TABLE 2, continued. Convergence and Divergence for Eight BEA Regions by Year

\begin{tabular}{|c|c|c|c|c|c|c|c|c|c|c|c|c|c|c|c|c|}
\hline & 85 & 86 & 87 & 88 & 89 & 90 & 91 & 92 & 93 & 94 & 95 & 96 & 97 & 98 & 99 & 00 \\
\hline 69 & 0 & 0 & 0 & 0 & 0 & 0 & 0 & 0 & 0 & 0 & 0 & 0 & 0 & 0 & 0 & 0 \\
\hline 70 & 0 & 0 & 0 & 0 & 0 & 0 & 0 & 0 & 0 & 0 & 0 & 0 & 0 & 0 & 0 & 0 \\
\hline 71 & 0 & 0 & 0 & 0 & 0 & 0 & 0 & 0 & 0 & 0 & 0 & 0 & 0 & 0 & 0 & 0 \\
\hline 72 & 0 & 0 & 0 & 0 & 0 & 0 & 0 & 0 & 0 & 0 & 0 & 0 & 0 & 0 & 0 & 0 \\
\hline 73 & 0 & 0 & 0 & 0 & 0 & 0 & 0 & 0 & 0 & 0 & 0 & 0 & 0 & 0 & 0 & 0 \\
\hline 74 & 0 & 0 & 0 & 0 & 0 & 0 & 0 & 0 & 0 & 0 & 0 & 0 & 0 & 0 & 0 & 0 \\
\hline 75 & 0 & 0 & 0 & 0 & 0 & 0 & 0 & 0 & 0 & 0 & 0 & 0 & 0 & 0 & 0 & 0 \\
\hline 76 & 0 & 0 & 0 & 0 & 0 & 0 & 0 & 0 & 0 & 0 & 0 & 0 & 0 & 0 & 0 & 0 \\
\hline 77 & 0 & 0 & 0 & 0 & 0 & 0 & 0 & 0 & 0 & 0 & 0 & 0 & 0 & 0 & 0 & 0 \\
\hline 78 & 0 & 0 & 0 & 0 & 0 & 0 & 0 & 0 & 0 & 0 & 0 & 0 & 0 & 0 & 0 & 0 \\
\hline 79 & 0 & 0 & 0 & 0 & 0 & 0 & 0 & 0 & 0 & 0 & 0 & 0 & 0 & 0 & 0 & 0 \\
\hline 80 & 0 & 0 & 0 & 0 & 0 & 0 & 0 & 0 & 0 & 0 & 0 & 0 & 0 & 0 & 0 & 0 \\
\hline 81 & 0 & 0 & 0 & 0 & 0 & 0 & 0 & 0 & 0 & 0 & 0 & 0 & 0 & 0 & 0 & 0 \\
\hline 82 & 0 & 0 & 0 & 0 & 0 & 0 & 0 & 0 & 0 & 0 & 0 & 0 & 0 & 0 & 0 & 0 \\
\hline 83 & 0 & 0 & 0 & 0 & 0 & 0 & 0 & 0 & 0 & 0 & 0 & 0 & 0 & 0 & 0 & 0 \\
\hline 84 & 0 & 0 & 0 & 0 & 0 & 0 & 0 & 0 & 0 & 0 & 0 & 0 & 0 & 0 & 0 & 0 \\
\hline 85 & 0 & 0 & 0 & 0 & 0 & 0 & 0 & 0 & 0 & 0 & 0 & 0 & 0 & 0 & 0 & 0 \\
\hline 86 & & 0 & 0 & 0 & 0 & 0 & 0 & 0 & 0 & 0 & 0 & 0 & 0 & 0 & 0 & 0 \\
\hline 87 & & & 0 & 0 & 0 & 0 & 0 & 0 & 0 & 0 & 0 & 0 & 0 & 0 & 0 & 0 \\
\hline 88 & & & & 0 & C & C & C & C & C & $\mathrm{C}$ & $\mathrm{C}$ & C & $\mathrm{C}$ & C & 0 & 0 \\
\hline 89 & & & & & 0 & C & C & C & C & $\mathrm{C}$ & $\mathrm{C}$ & 0 & 0 & 0 & 0 & 0 \\
\hline 90 & & & & & & C & 0 & C & C & $\mathrm{C}$ & 0 & 0 & 0 & 0 & 0 & 0 \\
\hline 91 & & & & & & & 0 & 0 & 0 & 0 & 0 & 0 & 0 & 0 & 0 & 0 \\
\hline 92 & & & & & & & & 0 & 0 & 0 & 0 & 0 & 0 & 0 & 0 & 0 \\
\hline 93 & & & & & & & & & 0 & 0 & 0 & 0 & 0 & 0 & 0 & 0 \\
\hline 94 & & & & & & & & & & 0 & 0 & 0 & 0 & 0 & 0 & 0 \\
\hline 95 & & & & & & & & & & & 0 & 0 & 0 & 0 & 0 & 0 \\
\hline 96 & & & & & & & & & & & & 0 & 0 & 0 & 0 & 0 \\
\hline 97 & & & & & & & & & & & & & 0 & 0 & 0 & 0 \\
\hline 98 & & & & & & & & & & & & & & 0 & 0 & 0 \\
\hline 99 & & & & & & & & & & & & & & & $\mathrm{D}$ & $\mathrm{D}$ \\
\hline 00 & & & & & & & & & & & & & & & & 0 \\
\hline
\end{tabular}

467 have negative slopes. Of these, 2 and 280 are significant respectively, resulting in relative frequencies of .03 and .59, respectively. For a randomly selected base year and end year, the probability of having a divergence in Alabama is 3 percent, and the probability of having a convergence is 59 percent. The idea of choosing a base and last year at random is based on the notion that the starting date for a study is random and the researchers act independently.

One way of determining the dependence of the negative and positive slopes on the number of counties is by regressing the number of negative and positive slopes on the number of counties for each state. The number of convergences, divergences, zeros, the relative frequencies 
of convergences, and the relative frequencies of divergences are regressed on the number of counties. The results are displayed in Table 6.

Note that the magnitudes of the slopes of regressions of the counts of negative and positive slopes on the number of counties in states are identical. However, the number of significant negative slopes (convergences) is much higher than the number of significant positive slopes (divergences). The latter is the only one that is not significant.

In summary, when testing for $\beta$-convergence, an increase in the number of observations results in higher counts of negative slopes, higher counts of significant negative slopes (convergence measure), greater chances for more significant negative slopes, and greater chances for positive slopes. It also results in lower counts of positive slopes and lower counts of insignificant slopes (zeros). Although the parameter for the number of divergences is not significant, the chance of concluding divergence is statistically significant and increases with the number of observations.

\section{SIMULATION}

In obtaining the above relative frequencies, neither the correlations nor the number of counties are controlled. Simulating the relation between the growth rate and the base year solves this problem and provides convergence or divergence under controlled conditions.

Table 4 provides convergence results for the 3,075 counties using per capita income for 1969 and the growth rate from 1969 to 2001. Per capita income converged between these two periods. The following dependent value is calculated for the negative association and convergence cases:

TABLE 3. Convergence and Divergence for Lower 48 States and the District of Columbia by Year

\begin{tabular}{|c|c|c|c|c|c|c|c|c|c|c|c|c|c|c|c|c|}
\hline & 69 & 70 & 71 & 72 & 73 & 74 & 75 & 76 & 77 & 78 & 79 & 80 & 81 & 82 & 83 & 84 \\
\hline 69 & $\mathrm{C}$ & $\mathrm{C}$ & $\mathrm{C}$ & $\mathrm{C}$ & $\mathrm{C}$ & $\mathrm{C}$ & $\mathrm{C}$ & $\mathrm{C}$ & $\mathrm{C}$ & $\mathrm{C}$ & $\mathrm{C}$ & $\mathrm{C}$ & $\mathrm{C}$ & $\mathrm{C}$ & $\mathrm{C}$ & $\mathrm{C}$ \\
\hline 70 & & $\mathrm{C}$ & $\mathrm{C}$ & $\mathrm{C}$ & $\mathrm{C}$ & $\mathrm{C}$ & $\mathrm{C}$ & $\mathrm{C}$ & $\mathrm{C}$ & $\mathrm{C}$ & C & $\mathrm{C}$ & $\mathrm{C}$ & $\mathrm{C}$ & $\mathrm{C}$ & $\mathrm{C}$ \\
\hline 71 & & & $\mathrm{C}$ & $\mathrm{C}$ & $\mathrm{C}$ & $\mathrm{C}$ & $\mathrm{C}$ & $\mathrm{C}$ & $\mathrm{C}$ & $\mathrm{C}$ & $\mathrm{C}$ & $\mathrm{C}$ & $\mathrm{C}$ & $\mathrm{C}$ & $\mathrm{C}$ & $\mathrm{C}$ \\
\hline 72 & & & & 0 & C & C & $\mathrm{C}$ & C & C & $\mathrm{C}$ & C & $\mathrm{C}$ & $\mathrm{C}$ & $\mathrm{C}$ & C & 0 \\
\hline 73 & & & & & 0 & 0 & C & C & $\mathrm{C}$ & C & C & $\mathrm{C}$ & $\mathrm{C}$ & C & C & 0 \\
\hline 74 & & & & & & 0 & $\mathrm{C}$ & 0 & $\mathrm{C}$ & $\mathrm{C}$ & 0 & 0 & 0 & 0 & 0 & 0 \\
\hline 75 & & & & & & & $\mathrm{C}$ & 0 & $\mathrm{C}$ & C & 0 & 0 & 0 & 0 & 0 & 0 \\
\hline 76 & & & & & & & & 0 & 0 & 0 & 0 & 0 & 0 & 0 & 0 & 0 \\
\hline 77 & & & & & & & & & 0 & 0 & 0 & 0 & 0 & 0 & 0 & 0 \\
\hline 78 & & & & & & & & & & 0 & 0 & 0 & 0 & 0 & 0 & 0 \\
\hline 79 & & & & & & & & & & & 0 & 0 & 0 & 0 & 0 & 0 \\
\hline 80 & & & & & & & & & & & & $\mathrm{C}$ & 0 & 0 & 0 & 0 \\
\hline 81 & & & & & & & & & & & & & 0 & 0 & 0 & 0 \\
\hline 82 & & & & & & & & & & & & & & 0 & 0 & 0 \\
\hline 83 & & & & & & & & & & & & & & & 0 & 0 \\
\hline 84 & & & & & & & & & & & & & & & & 0 \\
\hline
\end{tabular}

(C) Southern Regional Science Association 2009. 
TABLE 3, continued. Convergence and Divergence for Lower 48 States and the District of Columbia by Year

\begin{tabular}{|c|c|c|c|c|c|c|c|c|c|c|c|c|c|c|c|c|}
\hline & 85 & 86 & 87 & 88 & 89 & 90 & 91 & 92 & 93 & 94 & 95 & 96 & 97 & 98 & 99 & 00 \\
\hline 69 & $\mathrm{C}$ & $\mathrm{C}$ & 0 & 0 & 0 & $\mathrm{C}$ & $\mathrm{C}$ & $\mathrm{C}$ & $\mathrm{C}$ & $\mathrm{C}$ & $\mathrm{C}$ & $\mathrm{C}$ & $\mathrm{C}$ & $\mathrm{C}$ & 0 & $\mathrm{C}$ \\
\hline 70 & $\mathrm{C}$ & 0 & 0 & 0 & 0 & 0 & $\mathrm{C}$ & $\mathrm{C}$ & C & $\mathrm{C}$ & $\mathrm{C}$ & C & $\mathrm{C}$ & C & 0 & 0 \\
\hline 71 & 0 & 0 & 0 & 0 & 0 & 0 & 0 & 0 & C & $\mathrm{C}$ & $\mathrm{C}$ & C & 0 & 0 & 0 & 0 \\
\hline 72 & 0 & 0 & 0 & 0 & 0 & 0 & 0 & 0 & 0 & 0 & 0 & 0 & 0 & 0 & 0 & 0 \\
\hline 73 & 0 & 0 & 0 & 0 & 0 & 0 & 0 & 0 & C & $\mathrm{C}$ & $\mathrm{C}$ & 0 & 0 & 0 & 0 & 0 \\
\hline 74 & 0 & 0 & 0 & 0 & 0 & 0 & 0 & 0 & 0 & 0 & 0 & 0 & 0 & 0 & 0 & 0 \\
\hline 75 & 0 & 0 & 0 & 0 & 0 & 0 & 0 & 0 & 0 & 0 & 0 & 0 & 0 & 0 & 0 & 0 \\
\hline 76 & 0 & 0 & 0 & 0 & 0 & 0 & 0 & 0 & 0 & 0 & 0 & 0 & 0 & 0 & 0 & 0 \\
\hline 77 & 0 & 0 & 0 & 0 & 0 & 0 & 0 & 0 & 0 & 0 & 0 & 0 & 0 & 0 & 0 & 0 \\
\hline 78 & 0 & 0 & 0 & 0 & 0 & 0 & 0 & 0 & 0 & 0 & 0 & 0 & 0 & 0 & 0 & 0 \\
\hline 79 & 0 & 0 & 0 & 0 & 0 & 0 & 0 & 0 & 0 & 0 & 0 & 0 & 0 & 0 & 0 & 0 \\
\hline 80 & 0 & 0 & 0 & 0 & 0 & 0 & 0 & 0 & 0 & 0 & 0 & 0 & 0 & 0 & 0 & 0 \\
\hline 81 & 0 & 0 & 0 & 0 & 0 & 0 & 0 & 0 & 0 & 0 & 0 & 0 & 0 & 0 & 0 & 0 \\
\hline 82 & 0 & 0 & 0 & 0 & 0 & 0 & 0 & 0 & 0 & 0 & 0 & 0 & 0 & 0 & 0 & 0 \\
\hline 83 & 0 & 0 & 0 & 0 & 0 & 0 & 0 & 0 & 0 & 0 & 0 & 0 & 0 & 0 & 0 & 0 \\
\hline 84 & $\mathrm{D}$ & $\mathrm{D}$ & $\mathrm{D}$ & D & $\mathrm{D}$ & 0 & 0 & 0 & 0 & 0 & 0 & 0 & 0 & 0 & D & 0 \\
\hline 85 & $\mathrm{D}$ & D & $\mathrm{D}$ & D & D & 0 & 0 & 0 & 0 & 0 & 0 & 0 & 0 & 0 & 0 & 0 \\
\hline 86 & & $\mathrm{D}$ & $\mathrm{D}$ & D & D & 0 & 0 & 0 & 0 & 0 & 0 & 0 & 0 & 0 & 0 & 0 \\
\hline 87 & & & $\mathrm{D}$ & $\mathrm{D}$ & 0 & 0 & 0 & C & C & $\mathrm{C}$ & $\mathrm{C}$ & C & $\mathrm{C}$ & 0 & 0 & 0 \\
\hline 88 & & & & 0 & $\mathrm{C}$ & $\mathrm{C}$ & $\mathrm{C}$ & $\mathrm{C}$ & C & $\mathrm{C}$ & $\mathrm{C}$ & C & $\mathrm{C}$ & $\mathrm{C}$ & 0 & C \\
\hline 89 & & & & & $\mathrm{C}$ & C & $\mathrm{C}$ & $\mathrm{C}$ & C & $\mathrm{C}$ & $\mathrm{C}$ & C & $\mathrm{C}$ & 0 & 0 & 0 \\
\hline 90 & & & & & & C & $\mathrm{C}$ & $\mathrm{C}$ & C & $\mathrm{C}$ & $\mathrm{C}$ & C & $\mathrm{C}$ & C & 0 & 0 \\
\hline 91 & & & & & & & 0 & $\mathrm{C}$ & C & $\mathrm{C}$ & $\mathrm{C}$ & C & 0 & 0 & 0 & 0 \\
\hline 92 & & & & & & & & 0 & C & $\mathrm{C}$ & $\mathrm{C}$ & 0 & 0 & 0 & 0 & 0 \\
\hline 93 & & & & & & & & & $\mathrm{C}$ & $\mathrm{C}$ & 0 & 0 & 0 & 0 & 0 & 0 \\
\hline 94 & & & & & & & & & & 0 & 0 & 0 & 0 & 0 & D & $\mathrm{D}$ \\
\hline 95 & & & & & & & & & & & 0 & 0 & 0 & 0 & D & $\mathrm{D}$ \\
\hline 96 & & & & & & & & & & & & 0 & $\mathrm{D}$ & $\mathrm{D}$ & D & $\mathrm{D}$ \\
\hline 97 & & & & & & & & & & & & & 0 & $\mathrm{D}$ & D & $\mathrm{D}$ \\
\hline 98 & & & & & & & & & & & & & & 0 & $\mathrm{D}$ & $\mathrm{D}$ \\
\hline 99 & & & & & & & & & & & & & & & D & 0 \\
\hline 00 & & & & & & & & & & & & & & & & $\mathrm{C}$ \\
\hline
\end{tabular}

(4) $G=a+b X+E$,

where $G$ is the simulated value for the ratio of the last year in the study period, in this case 2001, to the first year, in this case 1969. The use of the ratio instead of the growth rate does not affect the slope, but the resulting intercept will exceed that of the intercept for the growth rate by 1.0. Also, $a$ is the value of the intercept obtained by regressing 3,075 county growth rate values for the years 1969 to 2001 on their 1969 per capita income; $b$ is the simulation slope, which is

(C) Southern Regional Science Association 2009. 
chosen in such a way that each of the corresponding correlation coefficients for the simulated data is almost equal to the values $-.1,-.2, \ldots,-.9 ; E$ is a computer-generated normal-zero-one random number using Excel software; and the estimated correlation coefficients are equal to the values above, which are accurate to three decimal places; and $X$ is the actual 1969 per capita income. Note that the relation between the slope and the correlation coefficient is:

(5) $\hat{\beta}_{1}=\hat{\rho} \sqrt{S_{Y Y} / S_{X X}}$,

where $S_{Y Y}$ and $S_{X X}$ are the sums of squares of the values for the dependent and independent variables, respectively.

The correlation coefficient for the 3,075 simulated data matches the actual, up to three decimal places. Any choice of intercept and slope would have worked; however, this approach yields simulated data that replicates the results based on all counties for the selected years. The third step in simulation is to take samples of sizes 3 through $10,20,50,100$, and 254 . The lowest and the highest sample sizes correspond to the number of counties in the state with the fewest counties (Delaware) and the most counties (Texas), respectively. In the case of samples of size 3, the first sample consists of observations 1,2 , and 3 . The second sample consists of observations 2,3 , and 4, and so on. In the case of sample size 254, the first sample consists of observations 1 , $2, \ldots$, and 254. The second sample consists of observations $2,3 \ldots 255$, and so on. The last sample for this group starts with observation number 2,822 and ends with observation number 3,075 . For the sake of consistency, the sample count for all sample sizes is kept at 2,822, the most that can be obtained for a sample size of 254. There are more than 2,822 possible ways to obtain a sample of size 254 from 3,075 observations. Instead of considering all of those possibilities, this simpler and more pragmatic approach is used. The number of simulations is large enough and suffices for the purpose at hand. First, negative correlations are considered, and then the positive correlations are used.

TABLE 4. Convergence and Divergence for 3,075 Counties by Year

\begin{tabular}{|c|c|c|c|c|c|c|c|c|c|c|c|c|c|c|c|c|}
\hline & 69 & 70 & 71 & 72 & 73 & 74 & 75 & 76 & 77 & 78 & 79 & 80 & 81 & 82 & 83 & 84 \\
\hline 69 & C & $\mathrm{C}$ & $\mathrm{C}$ & $\mathrm{C}$ & $\mathrm{C}$ & $\mathrm{C}$ & $\mathrm{C}$ & $\mathrm{C}$ & $\mathrm{C}$ & $\mathrm{C}$ & $\mathrm{C}$ & $\mathrm{C}$ & $\mathrm{C}$ & $\mathrm{C}$ & $\mathrm{C}$ & $\mathrm{C}$ \\
\hline 70 & & $\mathrm{C}$ & $\mathrm{C}$ & $\mathrm{C}$ & $\mathrm{C}$ & $\mathrm{C}$ & $\mathrm{C}$ & $\mathrm{C}$ & $\mathrm{C}$ & $\mathrm{C}$ & $\mathrm{C}$ & $\mathrm{C}$ & $\mathrm{C}$ & $\mathrm{C}$ & $\mathrm{C}$ & $\mathrm{C}$ \\
\hline 71 & & & C & $\mathrm{C}$ & $\mathrm{C}$ & C & $\mathrm{C}$ & $\mathrm{C}$ & $\mathrm{C}$ & C & $\mathrm{C}$ & $\mathrm{C}$ & $\mathrm{C}$ & $\mathrm{C}$ & C & $\mathrm{C}$ \\
\hline 72 & & & & 0 & $\mathrm{C}$ & C & $\mathrm{C}$ & $\mathrm{C}$ & $\mathrm{C}$ & C & $\mathrm{C}$ & $\mathrm{C}$ & $\mathrm{C}$ & $\mathrm{C}$ & C & $\mathrm{C}$ \\
\hline 73 & & & & & $\mathrm{C}$ & $\mathrm{C}$ & $\mathrm{C}$ & $\mathrm{C}$ & $\mathrm{C}$ & $\mathrm{C}$ & $\mathrm{C}$ & $\mathrm{C}$ & $\mathrm{C}$ & $\mathrm{C}$ & $\mathrm{C}$ & $\mathrm{C}$ \\
\hline 74 & & & & & & C & $\mathrm{C}$ & $\mathrm{C}$ & $\mathrm{C}$ & $\mathrm{C}$ & $\mathrm{C}$ & $\mathrm{C}$ & $\mathrm{C}$ & $\mathrm{C}$ & $\mathrm{C}$ & $\mathrm{C}$ \\
\hline 75 & & & & & & & $\mathrm{C}$ & $\mathrm{C}$ & $\mathrm{C}$ & $\mathrm{C}$ & $\mathrm{C}$ & $\mathrm{C}$ & $\mathrm{C}$ & $\mathrm{C}$ & $\mathrm{C}$ & $\mathrm{C}$ \\
\hline 76 & & & & & & & & $\mathrm{C}$ & $\mathrm{C}$ & $\mathrm{C}$ & $\mathrm{C}$ & C & $\mathrm{C}$ & $\mathrm{C}$ & C & $\mathrm{C}$ \\
\hline 77 & & & & & & & & & $\mathrm{C}$ & $\mathrm{C}$ & $\mathrm{C}$ & C & C & $\mathrm{C}$ & C & $\mathrm{C}$ \\
\hline 78 & & & & & & & & & & $\mathrm{C}$ & $\mathrm{C}$ & C & $\mathrm{C}$ & $\mathrm{C}$ & C & $\mathrm{C}$ \\
\hline 79 & & & & & & & & & & & $\mathrm{C}$ & $\mathrm{C}$ & $\mathrm{C}$ & $\mathrm{C}$ & $\mathrm{C}$ & $\mathrm{C}$ \\
\hline 80 & & & & & & & & & & & & C & $\mathrm{C}$ & $\mathrm{C}$ & C & $\mathrm{C}$ \\
\hline 81 & & & & & & & & & & & & & $\mathrm{C}$ & $\mathrm{C}$ & $\mathrm{C}$ & $\mathrm{C}$ \\
\hline 82 & & & & & & & & & & & & & & $\mathrm{C}$ & $\mathrm{C}$ & $\mathrm{C}$ \\
\hline 83 & & & & & & & & & & & & & & & $\mathrm{C}$ & $\mathrm{C}$ \\
\hline 84 & & & & & & & & & & & & & & & & $\mathrm{C}$ \\
\hline
\end{tabular}

(C) Southern Regional Science Association 2009. 
TABLE 4, continued. Convergence and Divergence for 3,075 Counties

\begin{tabular}{|c|c|c|c|c|c|c|c|c|c|c|c|c|c|c|c|c|}
\hline & 85 & 86 & 87 & 88 & 89 & 90 & 91 & 92 & 93 & 94 & 95 & 96 & 97 & 98 & 99 & 00 \\
\hline 69 & $\mathrm{C}$ & $\mathrm{C}$ & $\mathrm{C}$ & $\mathrm{C}$ & $\mathrm{C}$ & $\mathrm{C}$ & $\mathrm{C}$ & $\mathrm{C}$ & $\mathrm{C}$ & $\mathrm{C}$ & $\mathrm{C}$ & $\mathrm{C}$ & $\mathrm{C}$ & $\mathrm{C}$ & $\mathrm{C}$ & $\mathrm{C}$ \\
\hline 70 & $\mathrm{C}$ & $\mathrm{C}$ & $\mathrm{C}$ & $\mathrm{C}$ & $\mathrm{C}$ & $\mathrm{C}$ & $\mathrm{C}$ & $\mathrm{C}$ & C & $\mathrm{C}$ & $\mathrm{C}$ & $\mathrm{C}$ & $\mathrm{C}$ & C & $\mathrm{C}$ & $\mathrm{C}$ \\
\hline 71 & $\mathrm{C}$ & $\mathrm{C}$ & $\mathrm{C}$ & $\mathrm{C}$ & $\mathrm{C}$ & $\mathrm{C}$ & $\mathrm{C}$ & $\mathrm{C}$ & $\mathrm{C}$ & $\mathrm{C}$ & $\mathrm{C}$ & $\mathrm{C}$ & $\mathrm{C}$ & $\mathrm{C}$ & $\mathrm{C}$ & C \\
\hline 72 & $\mathrm{C}$ & $\mathrm{C}$ & C & $\mathrm{C}$ & $\mathrm{C}$ & $\mathrm{C}$ & $\mathrm{C}$ & C & $\mathrm{C}$ & $\mathrm{C}$ & $\mathrm{C}$ & $\mathrm{C}$ & $\mathrm{C}$ & $\mathrm{C}$ & $\mathrm{C}$ & C \\
\hline 73 & $\mathrm{C}$ & C & C & C & $\mathrm{C}$ & $\mathrm{C}$ & $\mathrm{C}$ & C & $\mathrm{C}$ & $\mathrm{C}$ & C & $\mathrm{C}$ & $\mathrm{C}$ & $\mathrm{C}$ & $\mathrm{C}$ & C \\
\hline 74 & $\mathrm{C}$ & $\mathrm{C}$ & $\mathrm{C}$ & $\mathrm{C}$ & C & $\mathrm{C}$ & $\mathrm{C}$ & C & $\mathrm{C}$ & $\mathrm{C}$ & C & $\mathrm{C}$ & $\mathrm{C}$ & $\mathrm{C}$ & $\mathrm{C}$ & $\mathrm{C}$ \\
\hline 75 & C & C & C & C & $\mathrm{C}$ & C & $\mathrm{C}$ & C & $\mathrm{C}$ & $\mathrm{C}$ & C & $\mathrm{C}$ & $\mathrm{C}$ & $\mathrm{C}$ & C & C \\
\hline 76 & $\mathrm{C}$ & $\mathrm{C}$ & C & $\mathrm{C}$ & $\mathrm{C}$ & $\mathrm{C}$ & $\mathrm{C}$ & C & $\mathrm{C}$ & $\mathrm{C}$ & $\mathrm{C}$ & $\mathrm{C}$ & $\mathrm{C}$ & $\mathrm{C}$ & $\mathrm{C}$ & C \\
\hline 77 & $\mathrm{C}$ & C & C & $\mathrm{C}$ & C & C & $\mathrm{C}$ & C & $\mathrm{C}$ & $\mathrm{C}$ & C & C & $\mathrm{C}$ & C & C & $\mathrm{C}$ \\
\hline 78 & $\mathrm{C}$ & C & C & $\mathrm{C}$ & C & C & $\mathrm{C}$ & C & $\mathrm{C}$ & $\mathrm{C}$ & C & C & $\mathrm{C}$ & C & C & $\mathrm{C}$ \\
\hline 79 & $\mathrm{C}$ & C & C & $\mathrm{C}$ & C & C & $\mathrm{C}$ & C & $\mathrm{C}$ & $\mathrm{C}$ & C & $\mathrm{C}$ & $\mathrm{C}$ & $\mathrm{C}$ & C & $\mathrm{C}$ \\
\hline 80 & $\mathrm{C}$ & C & $\mathrm{C}$ & $\mathrm{C}$ & C & $\mathrm{C}$ & $\mathrm{C}$ & $\mathrm{C}$ & $\mathrm{C}$ & $\mathrm{C}$ & $\mathrm{C}$ & $\mathrm{C}$ & $\mathrm{C}$ & C & $\mathrm{C}$ & $\mathrm{C}$ \\
\hline 81 & $\mathrm{C}$ & C & C & $\mathrm{C}$ & C & C & $\mathrm{C}$ & C & $\mathrm{C}$ & $\mathrm{C}$ & C & C & $\mathrm{C}$ & $\mathrm{C}$ & C & C \\
\hline 82 & $\mathrm{C}$ & C & C & $\mathrm{C}$ & C & C & $\mathrm{C}$ & C & $\mathrm{C}$ & $\mathrm{C}$ & C & C & $\mathrm{C}$ & C & C & C \\
\hline 83 & $\mathrm{C}$ & C & $\mathrm{C}$ & $\mathrm{C}$ & C & $\mathrm{C}$ & $\mathrm{C}$ & $\mathrm{C}$ & $\mathrm{C}$ & $\mathrm{C}$ & $\mathrm{C}$ & $\mathrm{C}$ & $\mathrm{C}$ & $\mathrm{C}$ & $\mathrm{C}$ & $\mathrm{C}$ \\
\hline 84 & C & C & C & C & C & C & $\mathrm{C}$ & C & $\mathrm{C}$ & $\mathrm{C}$ & C & $\mathrm{C}$ & $\mathrm{C}$ & $\mathrm{C}$ & $\mathrm{C}$ & C \\
\hline 85 & $\mathrm{C}$ & C & C & C & C & C & $\mathrm{C}$ & C & $\mathrm{C}$ & $\mathrm{C}$ & C & $\mathrm{C}$ & $\mathrm{C}$ & $\mathrm{C}$ & $\mathrm{C}$ & C \\
\hline 86 & & C & C & $\mathrm{C}$ & C & C & $\mathrm{C}$ & $\mathrm{C}$ & $\mathrm{C}$ & $\mathrm{C}$ & C & $\mathrm{C}$ & $\mathrm{C}$ & $\mathrm{C}$ & $\mathrm{C}$ & C \\
\hline 87 & & & 0 & C & C & C & $\mathrm{C}$ & C & $\mathrm{C}$ & $\mathrm{C}$ & C & $\mathrm{C}$ & $\mathrm{C}$ & $\mathrm{C}$ & $\mathrm{C}$ & C \\
\hline 88 & & & & $\mathrm{C}$ & C & $\mathrm{C}$ & $\mathrm{C}$ & $\mathrm{C}$ & $\mathrm{C}$ & $\mathrm{C}$ & $\mathrm{C}$ & $\mathrm{C}$ & $\mathrm{C}$ & $\mathrm{C}$ & $\mathrm{C}$ & C \\
\hline 89 & & & & & C & C & $\mathrm{C}$ & C & $\mathrm{C}$ & 0 & 0 & $\mathrm{D}$ & $\mathrm{D}$ & $\mathrm{D}$ & D & $\mathrm{D}$ \\
\hline 90 & & & & & & $\mathrm{C}$ & $\mathrm{C}$ & C & $\mathrm{C}$ & $\mathrm{C}$ & C & $\mathrm{C}$ & $\mathrm{C}$ & $\mathrm{C}$ & $\mathrm{C}$ & C \\
\hline 91 & & & & & & & $\mathrm{C}$ & $\mathrm{C}$ & $\mathrm{C}$ & $\mathrm{C}$ & C & C & $\mathrm{C}$ & 0 & 0 & 0 \\
\hline 92 & & & & & & & & C & $\mathrm{C}$ & $\mathrm{C}$ & 0 & 0 & $\mathrm{D}$ & D & D & D \\
\hline 93 & & & & & & & & & $\mathrm{C}$ & C & C & C & 0 & D & D & 0 \\
\hline 94 & & & & & & & & & & 0 & D & D & $\mathrm{D}$ & D & D & D \\
\hline 95 & & & & & & & & & & & 0 & 0 & $\mathrm{D}$ & $\mathrm{D}$ & D & D \\
\hline 96 & & & & & & & & & & & & $\mathrm{C}$ & 0 & 0 & D & 0 \\
\hline 97 & & & & & & & & & & & & & 0 & D & D & D \\
\hline 98 & & & & & & & & & & & & & & 0 & D & $\mathrm{D}$ \\
\hline 99 & & & & & & & & & & & & & & & D & 0 \\
\hline 00 & & & & & & & & & & & & & & & & $\mathrm{C}$ \\
\hline
\end{tabular}

Table 7 reports the number of significant correlation coefficients for each of the negative correlation values used in the simulation. These reflect the number of convergences for different negative correlation values and sample sizes. Note that as the absolute value of the correlation coefficient increases, the number of convergences increase, and as the sample size increases, the number of convergences increase.

The procedure for positive correlations is the same, except the values of correlation coefficients are positive. Table 8 reports the counts of significant correlation coefficients for each of the positive correlation values utilized in the simulation. Here, too, as the absolute value of the 
TABLE 5. Counts of Negative, Positive, Convergence, Divergence, Non-significant Slopes, Probability of Convergence, and Probability of Divergence in 528 Regressions for Each U.S. State

\begin{tabular}{|c|c|c|c|c|c|c|c|c|c|}
\hline & Counties & Negative & Positive & 0s & Cs & Ds & C Freq & D Freq & Total \\
\hline Alabama & 67 & 467 & 61 & 246 & 280 & 2 & .60 & .033 & 528 \\
\hline Arizona & 14 & 276 & 252 & 478 & 33 & 17 & 12 & .067 & 528 \\
\hline Arkansas & 75 & 484 & 44 & 153 & 369 & 6 & .76 & .136 & 528 \\
\hline California & 58 & 80 & 448 & 186 & 19 & 323 & .24 & .721 & 528 \\
\hline Colorado & 63 & 435 & 93 & 188 & 308 & 32 & .71 & .344 & 528 \\
\hline Connecticut & 8 & 80 & 448 & 375 & 2 & 151 & .03 & .337 & 528 \\
\hline Delaware & 3 & 137 & 391 & 509 & 3 & 16 & .02 & .041 & 528 \\
\hline Florida & 67 & 188 & 340 & 434 & 39 & 55 & .21 & .162 & 528 \\
\hline Georgia & 159 & 451 & 77 & 113 & 367 & 48 & .81 & .623 & 528 \\
\hline Idaho & 44 & 441 & 87 & 352 & 165 & 11 & .37 & . 126 & 528 \\
\hline Illinois & 102 & 415 & 113 & 252 & 242 & 34 & .58 & .301 & 528 \\
\hline Indiana & 92 & 335 & 193 & 388 & 112 & 28 & .33 & 145 & 528 \\
\hline Iowa & 99 & 501 & 27 & 99 & 420 & 9 & 84 & .333 & 528 \\
\hline Kansas & 105 & 495 & 33 & 59 & 458 & 11 & .93 & .333 & 528 \\
\hline Kentucky & 120 & 460 & 68 & 153 & 368 & 7 & .80 & 103 & 528 \\
\hline Louisiana & 64 & 461 & 67 & 179 & 336 & 13 & .73 & . 194 & 528 \\
\hline Maine & 16 & 158 & 370 & 470 & 29 & 29 & .18 & .078 & 528 \\
\hline Maryland & 24 & 138 & 390 & 506 & 11 & 11 & .08 & .028 & 528 \\
\hline Massachusetts & 14 & 112 & 416 & 344 & 35 & 149 & .31 & .358 & 528 \\
\hline Michigan & 83 & 225 & 303 & 406 & 52 & 70 & .23 & .231 & 528 \\
\hline Minnesota & 87 & 489 & 39 & 147 & 376 & 5 & .77 & 128 & 528 \\
\hline Mississippi & 82 & 435 & 93 & 227 & 265 & 36 & .61 & .387 & 528 \\
\hline Missouri & 115 & 477 & 51 & 133 & 390 & 5 & .82 & .098 & 528 \\
\hline Montana & 56 & 490 & 38 & 95 & 422 & 11 & .86 & 289 & 528 \\
\hline Nebraska & 93 & 456 & 72 & 164 & 329 & 35 & .72 & .486 & 528 \\
\hline Nevada & 17 & 451 & 77 & 378 & 140 & 10 & .31 & .130 & 528 \\
\hline New Hampshire & 10 & 275 & 253 & 485 & 28 & 15 & 10 & .059 & 528 \\
\hline New Jersey & 21 & 24 & 504 & 163 & 0 & 365 & .00 & .724 & 528 \\
\hline New Mexico & 32 & 399 & 129 & 452 & 75 & 1 & .19 & .008 & 528 \\
\hline New York & 62 & 37 & 491 & 153 & 5 & 370 & 14 & .754 & 528 \\
\hline North Carolina & 100 & 420 & 108 & 239 & 272 & 17 & .65 & 157 & 528 \\
\hline North Dakota & 53 & 484 & 44 & 179 & 343 & 6 & .71 & .136 & 528 \\
\hline Ohio & 88 & 211 & 317 & 342 & 86 & 100 & 41 & .315 & 528 \\
\hline Oklahoma & 77 & 493 & 35 & 100 & 425 & 3 & .86 & .086 & 528 \\
\hline Oregon & 36 & 420 & 108 & 151 & 316 & 61 & .75 & .565 & 528 \\
\hline Pennsylvania & 67 & 126 & 402 & 354 & 42 & 132 & .33 & .328 & 528 \\
\hline Rhode Island & 6 & 298 & 230 & 507 & 12 & 9 & .04 & .039 & 528 \\
\hline South Carolina & 46 & 350 & 178 & 413 & 87 & 28 & .25 & 157 & 528 \\
\hline South Dakota & 66 & 446 & 82 & 370 & 153 & 5 & .34 & .061 & 528 \\
\hline Tennessee & 95 & 435 & 93 & 294 & 220 & 14 & .51 & .151 & 528 \\
\hline Texas & 254 & 498 & 30 & 41 & 473 & 14 & .95 & .467 & 528 \\
\hline Utah & 29 & 369 & 159 & 476 & 29 & 23 & .08 & 145 & 528 \\
\hline Vermont & 14 & 66 & 462 & 412 & 5 & 111 & .08 & .240 & 528 \\
\hline Virginia & 105 & 321 & 207 & 405 & 76 & 47 & .24 & .227 & 528 \\
\hline Washington & 39 & 379 & 149 & 243 & 229 & 56 & .60 & .376 & 528 \\
\hline West Virginia & 55 & 435 & 93 & 225 & 299 & 4 & .69 & .043 & 528 \\
\hline Wisconsin & 70 & 189 & 339 & 370 & 70 & 88 & .37 & .260 & 528 \\
\hline Wyoming & 23 & 394 & 134 & 495 & 27 & 6 & .07 & .045 & 528 \\
\hline Regions & 8 & 396 & 132 & 463 & 63 & 2 & .16 & .015 & 528 \\
\hline States & 48 & 389 & 140 & 351 & 146 & 31 & .38 & .021 & 528 \\
\hline All Counties & 3,075 & 488 & 40 & 20 & 480 & 28 & .98 & .700 & 528 \\
\hline
\end{tabular}

(C) Southern Regional Science Association 2009. 
TABLE 6. Slopes of Regressions between the Counts of Negative, Positive, Zeros, and Probabilities for Convergence and Divergence upon the Number of Counties in States

\begin{tabular}{lrrl}
\hline \hline Dependent Variable & \multicolumn{1}{c}{ Slope } & \multicolumn{1}{c}{$p$-Value } & \multicolumn{1}{c}{$R^{2}$} \\
\hline Negative Slopes & 1.57 & .000659 & .2250 \\
Positive Slopes & -1.57 & .000659 & .2250 \\
Zeros & -1.93 & .00000283 & .3822 \\
Convergences & 2.24 & .00000270 & .4255 \\
Divergences & -0.308 & .272 & .0262 \\
Relative Frequency of Convergences & 0.0045 & .0000000423 & .4685 \\
Relative Frequency of Divergences & 0.0012 & .0461 & .0804 \\
\hline \hline
\end{tabular}

TABLE 7. The Number of Convergences for 2,822 Samples Sized 3 through 254 Using Different Negative Correlation Coefficients

\begin{tabular}{l|rrrrrrrrrrrrrr}
\hline \hline$\rho$ & 3 & 4 & 5 & 6 & 7 & 8 & 9 & 10 & 20 & 50 & 100 & 150 & 200 & 254 \\
-.1 & 81 & 105 & 124 & 126 & 156 & 162 & 177 & 194 & 305 & 761 & 1301 & 1781 & 2230 & 2555 \\
-.2 & 97 & 150 & 189 & 232 & 276 & 312 & 336 & 376 & 770 & 1664 & 2499 & 2758 & 2822 & 2822 \\
-.3 & 119 & 197 & 258 & 342 & 404 & 476 & 528 & 603 & 1267 & 2312 & 2764 & 2822 & 2822 & 2822 \\
-.4 & 132 & 244 & 328 & 441 & 533 & 623 & 742 & 831 & 1569 & 2605 & 2821 & 2822 & 2822 & 2822 \\
-.5 & 147 & 292 & 389 & 542 & 650 & 789 & 914 & 1016 & 1845 & 2714 & 2822 & 2822 & 2822 & 2822 \\
-.6 & 166 & 328 & 448 & 630 & 779 & 933 & 1066 & 1167 & 2049 & 2768 & 2822 & 2822 & 2822 & 2822 \\
-.7 & 178 & 352 & 522 & 716 & 899 & 1071 & 1224 & 1346 & 2200 & 2794 & 2822 & 2822 & 2822 & 2822 \\
-.8 & 191 & 382 & 590 & 809 & 994 & 1196 & 1344 & 1497 & 2333 & 2809 & 2822 & 2822 & 2822 & 2822 \\
-.9 & 202 & 412 & 644 & 876 & 10931295 & 1448 & 1610 & 2448 & 2816 & 2822 & 2822 & 2822 & 2822 \\
\hline \hline
\end{tabular}

TABLE 8. The Number of Divergences for 2,822 Samples Sized 3 through 254 Using Different Positive Correlation Coefficients

\begin{tabular}{r|rrrrrrrrrrrrrr}
\hline \hline \multicolumn{1}{l}{$\rho$} & 3 & 4 & 5 & 6 & 7 & 8 & 9 & 10 & 20 & 50 & 100 & 150 & 200 & 254 \\
\hline .1 & 82 & 82 & 80 & 89 & 90 & 90 & 107 & 107 & 143 & 161 & 227 & 269 & 344 & 304 \\
.2 & 85 & 95 & 91 & 103 & 99 & 114 & 134 & 135 & 170 & 255 & 415 & 550 & 569 & 758 \\
.3 & 89 & 105 & 110 & 123 & 124 & 145 & 164 & 169 & 238 & 510 & 771 & 1019 & 1311 & 1623 \\
.4 & 94 & 121 & 138 & 161 & 170 & 201 & 229 & 237 & 384 & 865 & 1450 & 1930 & 2228 & 2540 \\
.5 & 105 & 142 & 181 & 213 & 245 & 300 & 320 & 332 & 639 & 1461 & 2201 & 2527 & 2724 & 2782 \\
.6 & 117 & 194 & 255 & 325 & 396 & 447 & 509 & 556 & 1091 & 2057 & 2594 & 2729 & 2808 & 2822 \\
.7 & 150 & 290 & 420 & 546 & 667 & 787 & 897 & 1012 & 1827 & 2562 & 2817 & 2822 & 2822 & 2822 \\
.8 & 226 & 512 & 801 & 1016 & 1249 & 1452 & 1625 & 1779 & 2473 & 2752 & 2822 & 2822 & 2822 & 2822 \\
.9 & 455 & 1152 & 1750 & 2143 & 2353 & 2498 & 2584 & 2654 & 2812 & 2822 & 2822 & 2822 & 2822 & 2822 \\
\hline \hline
\end{tabular}

(C) Southern Regional Science Association 2009. 
correlation coefficient or the sample size increases, the number of significant cases (i.e., divergences) increases.

The numbers of convergences and divergences are very close when the sample size is small and the correlation is low in absolute value. For a given correlation, as the sample size increases, the number of convergences increases more rapidly than the number of divergences, especially, for low correlation coefficients. This is similar to the reported convergences in the literature, as well as the results for the counties within the states, as reported in Table 5. For a given sample size, as the absolute value of the correlation coefficient increases, the number of divergences increases more rapidly than the number of convergences. This implies that for a given sample size, a larger correlation (in absolute value) is necessary for divergence as it is for convergence. Once again, this is supported by empirical evidence reported in the literature.

For ease of interpretation, the numbers can be converted to probabilities. There are two ways of obtaining probabilities for the convergences and divergences. One way is by dividing the number of significant convergences and divergences by 2,822. Another way is to divide the number of convergences by the number of negative correlations, and to divide the number of divergences by the number of positive correlations. This is similar to the "relative frequencies" reported in Table 5. Table 9 provides the two sets of probabilities for convergences, and Table 10 provides the two sets of probabilities for divergences.

According to these tables, in 2,822 samples of size 254 each, if the correlation coefficient is -.1, there is 10.8 percent chance of declaring convergence. When the sample size is reduced to 50 , the probability of convergence reduces to 5.7 percent. In order for the smaller sample to have a probability of convergence comparable to the larger sample, its actual correlation coefficient has to exceed .3. With a sample of size 4 , the correlation coefficient has to be greater than .7 to provide the same probability.

\section{CONCLUSIONS}

One way of studying trends in income inequality is through $\beta$-convergence. $\beta$ convergence addresses the change in the position of economies. It indicates that the poorer economies are catching up with the richer economies. The common approach is to regress per capita income's growth rate over a period on the initial period's per capita income. A negative and statistically significant slope indicates $\beta$-convergence, while a positive and statistically significant slope indicates $\beta$-divergence.

Although the conclusion of convergence or divergence is a function of the correlation between the per capita income of the base year and the growth rate of income between the base year and any period $T$ years away from the base, it is also a function of the observations in the sample. The influence of the latter has been ignored in the cross-section studies of convergence.

A finding of this study is that with U.S. per capita income for the latter part of the twentieth century, the choice of the beginning and ending periods makes a difference in the conclusion of convergence or divergence. For example, in case of the states, if the period is from 1969 to 1999 the conclusion is that there is no convergence or divergence. If the period is extended by one year to the year 2000, however, the conclusion is convergence. There are clusters of convergence, divergence, and insignificant results. The clusters are larger, especially for convergence, when counties are used, indicating the influence of larger sample size.

(C) Southern Regional Science Association 2009. 
TABLE 9A. Probability of Significant Convergence for Different Parameters and Sample Sizes Using 2,822 Simulations

\begin{tabular}{r|rrrrrrrrrrrrrr}
\hline \hline \multicolumn{1}{c}{$\rho$} & 3 & 4 & 5 & 6 & 7 & 8 & 9 & 10 & 20 & 50 & 100 & 150 & 200 & 254 \\
\hline-.1 & .03 & .04 & .04 & .04 & .06 & .06 & .06 & .07 & .11 & .27 & .46 & .63 & .79 & .91 \\
-.2 & .03 & .05 & .07 & .08 & .10 & .11 & .12 & .13 & .27 & .59 & .89 & .98 & 1.00 & 1.00 \\
-.3 & .04 & .07 & .09 & .12 & .14 & .17 & .19 & .21 & .45 & .82 & .98 & 1.00 & 1.00 & 1.00 \\
-.4 & .05 & .09 & .12 & .16 & .19 & .22 & .26 & .29 & .56 & .92 & 1.00 & 1.00 & 1.00 & 1.00 \\
-.5 & .05 & .10 & .14 & .19 & .23 & .28 & .32 & .36 & .65 & .96 & 1.00 & 1.00 & 1.00 & 1.00 \\
-.6 & .06 & .12 & .16 & .22 & .28 & .33 & .38 & .41 & .73 & .98 & 1.00 & 1.00 & 1.00 & 1.00 \\
-.7 & .06 & .12 & .18 & .25 & .32 & .38 & .43 & .48 & .78 & .99 & 1.00 & 1.00 & 1.00 & 1.00 \\
-.8 & .07 & .14 & .21 & .29 & .35 & .42 & .48 & .53 & .83 & 1.00 & 1.00 & 1.00 & 1.00 & 1.00 \\
-.9 & .07 & .15 & .23 & .31 & .39 & .46 & .51 & .57 & .87 & 1.00 & 1.00 & 1.00 & 1.00 & 1.00 \\
\hline \hline
\end{tabular}

TABLE 9B. Probability of Significant Convergence for Different Parameters and Sample Sizes Using 2,822 Simulations

\begin{tabular}{r|rrrrrrrrrrrrrr}
\hline \hline \multicolumn{1}{l}{$\rho$} & 3 & 4 & 5 & 6 & 7 & 8 & 9 & 10 & 20 & 50 & 100 & 150 & 200 & 254 \\
\hline-.1 & .05 & .06 & .07 & .07 & .09 & .09 & .10 & .10 & .15 & .31 & .49 & .64 & .79 & .91 \\
-.2 & .05 & .08 & .10 & .11 & .13 & .15 & .16 & .17 & .32 & .61 & .89 & .98 & 1.00 & 1.00 \\
-.3 & .06 & .10 & .12 & .15 & .18 & .21 & .22 & .25 & .48 & .83 & .98 & 1.00 & 1.00 & 1.00 \\
-.4 & .07 & .11 & .14 & .19 & .22 & .26 & .30 & .33 & .57 & .92 & 1.00 & 1.00 & 1.00 & 1.00 \\
-.5 & .07 & .13 & .16 & .22 & .26 & .31 & .35 & .39 & .66 & .96 & 1.00 & 1.00 & 1.00 & 1.00 \\
-.6 & .08 & .14 & .18 & .25 & .30 & .36 & .41 & .44 & .73 & .98 & 1.00 & 1.00 & 1.00 & 1.00 \\
-.7 & .08 & .15 & .21 & .28 & .35 & .41 & .46 & .50 & .78 & .99 & 1.00 & 1.00 & 1.00 & 1.00 \\
-.8 & .09 & .16 & .23 & .31 & .38 & .45 & .50 & .55 & .83 & 1.00 & 1.00 & 1.00 & 1.00 & 1.00 \\
-.9 & .09 & .17 & .25 & .34 & .41 & .48 & .53 & .59 & .87 & 1.00 & 1.00 & 1.00 & 1.00 & 1.00 \\
\hline \hline
\end{tabular}

For any period of length $T$, there are $T(T-1) / 2$ growth rates, hence, there are as many tests of $\beta$-convergences. This paper studies the period 1969 to 2001 . There are 534 possible comparisons for each state. Of the 25,344 possible cases for the lower 48 states, 16,206 (or 63.94 percent) have negative slopes, while the remaining 9,138 have positive slopes. There are 8,842 (34.89 percent) negative and significant slopes (indicating convergence), 2,599 (10.25 percent) positive and significant slopes (indicating divergence), and the remaining 13,903 (54.86 percent) are not significant. Therefore, for any two randomly selected years for any given state, the most likely outcome is lack of significance, followed by convergence. Since there are more convergences than divergences, the per capita incomes of counties within the states in the U.S. have more tendencies for convergence than for divergence. Furthermore, among the states, those with more counties are more likely to generate the convergence conclusion than those with fewer counties. The slope of the regression of number of convergences per state on the number of counties in the state (sample sizes) is positive and significant. This indicates that as the number of counties increases, the number of significant slopes (convergences) increases. 
TABLE 10A. Probability of Significant Divergences for Different Parameters and Sample Sizes Using 2,822 Simulations

\begin{tabular}{r|rrrrrrrrrrrrrr}
\hline \multicolumn{1}{l}{$\rho$} & 3 & 4 & 5 & 6 & 7 & 8 & 9 & 10 & 20 & 50 & 100 & 150 & 200 & 254 \\
\hline .1 & .03 & .03 & .03 & .03 & .03 & .03 & .04 & .04 & .05 & .06 & .08 & .10 & .12 & .11 \\
.2 & .03 & .03 & .03 & .04 & .04 & .04 & .05 & .05 & .06 & .09 & .15 & .19 & .20 & .27 \\
.3 & .03 & .04 & .04 & .04 & .04 & .05 & .06 & .06 & .08 & .18 & .27 & .36 & .46 & .58 \\
.4 & .03 & .04 & .05 & .06 & .06 & .07 & .08 & .08 & .14 & .31 & .51 & .68 & .79 & .90 \\
.5 & .04 & .05 & .06 & .08 & .09 & .11 & .11 & .12 & .23 & .52 & .78 & .90 & .97 & .99 \\
.6 & .04 & .07 & .09 & .12 & .14 & .16 & .18 & .20 & .39 & .73 & .92 & .97 & 1.00 & 1.00 \\
.7 & .05 & .10 & .15 & .19 & .24 & .28 & .32 & .36 & .65 & .91 & 1.00 & 1.00 & 1.00 & 1.00 \\
.8 & .08 & .18 & .28 & .36 & .44 & .51 & .58 & .63 & .88 & .98 & 1.00 & 1.00 & 1.00 & 1.00 \\
.9 & .16 & .41 & .62 & .76 & .83 & .89 & .92 & .94 & 1.00 & 1.00 & 1.00 & 1.00 & 1.00 & 1.00 \\
\hline \hline
\end{tabular}

TABLE 10B. Probability of Significant Divergences for Different Parameters and Sample Sizes Using 2,822 Simulations

\begin{tabular}{r|rrrrrrrrrrrrrr}
\hline \hline \multicolumn{1}{l}{$\rho$} & 3 & 4 & 5 & 6 & 7 & 8 & 9 & 10 & 20 & 50 & 100 & 150 & 200 & 254 \\
\hline .1 & .06 & .06 & .05 & .06 & .06 & .06 & .07 & .07 & .09 & .09 & .12 & .14 & .17 & .15 \\
.2 & .06 & .06 & .06 & .07 & .06 & .07 & .08 & .08 & .10 & .13 & .19 & .24 & .24 & .31 \\
.3 & .06 & .06 & .07 & .07 & .07 & .08 & .09 & .09 & .12 & .24 & .31 & .39 & .49 & .59 \\
.4 & .06 & .07 & .08 & .09 & .09 & .10 & .12 & .12 & .17 & .35 & .55 & .71 & .80 & .90 \\
.5 & .06 & .08 & .09 & .11 & .12 & .14 & .15 & .15 & .26 & .56 & .80 & .90 & .97 & .99 \\
.6 & .06 & .10 & .12 & .15 & .18 & .19 & .22 & .24 & .42 & .76 & .92 & .97 & 1.00 & 1.00 \\
.7 & .07 & .13 & .18 & .23 & .27 & .31 & .35 & .39 & .68 & .92 & 1.00 & 1.00 & 1.00 & 1.00 \\
.8 & .10 & .21 & .31 & .39 & .47 & .54 & .60 & .65 & .89 & .98 & 1.00 & 1.00 & 1.00 & 1.00 \\
.9 & .17 & .42 & .63 & .77 & .84 & .89 & .92 & .94 & 1.00 & 1.00 & 1.00 & 1.00 & 1.00 & 1.00 \\
\hline \hline
\end{tabular}

Since the correlation between the dependent and the independent variable, as well as the number of observations in the sample, affect the conclusion, one should be careful of the conclusion of $\beta$-convergence using regression analysis. The present study provides the probability of concluding convergence, divergence, or lack of significance in two ways. One is based on the actual data for the counties in the lower 48 states in the U.S. The other is based on 355,572 simulations using correlation coefficients between the dependent and independent variables in increments of .1 and sample sizes 3 through 10 and 20, 50, 100, 150, 200, and 254. There are 2,822 simulations for each of nine positive and nine negative correlation coefficients and 14 sample sizes mentioned above. In both cases, as expected, as the sample size or the absolute value of the correlation coefficient increases, the number of significant outcomes, both convergence and divergence, increases. The simulation results indicate slightly more divergence than convergence, while the actual data points to the opposite. Therefore, during the period 1969 to 2001, negative correlation between the base year and the end year is dominant, supporting the claim of overall convergence. This conclusion is based on the number of pair wise comparisons and is immune to the selection of specific base and ending year. This conclusion would not have been possible if the slopes were used instead of the correlation coefficient because the former

(C) Southern Regional Science Association 2009. 
represents the combined effect of the correlation coefficient and the sample size on the conclusion of significance.

One possible extension of existing literature is to account for spatial correlations between adjacent regions, especially at the country level analysis. The maximum likelihood method can be used to obtain estimates of spatial correlations between the vector of growth rates and the average growth rates of neighboring counties.

\section{RECOMMENDATIONS}

This study demonstrates that in addition to the already known pitfalls of using regression analysis to study convergence, there is another problem. The basic message is that sample size matters, but not in the traditional sense of statistical analysis where larger sample sizes are preferred. The importance of sample size in the context of this study is based on two pillars. One is temporal in nature and the other reflects the unit of measurement. The former represents the time distance between the beginning and ending of the study period, while the latter is a function of the unit of study such as counties, states, and regions. A given country can be divided into regions, which in turn include states, each of which contain different numbers of counties. The combination of these two factors, unit of study and the time horizon, determine the sample size which is shown here to make a difference in the test of $\beta$-convergence. The outcome of convergence, divergence, or lack of significance is influenced by both the actual correlation between the beginning and ending date as well as the temporal distance of the two points. Therefore, it is advisable not to compare the results of studies with differing units and time windows. In other words, the outcomes of studies using regions as units should not be compared to the outcomes of studies using other units such as states or counties. Furthermore, for a given unit of study, the time window should be of equal length to avoid the effect of temporal influence.

When the purpose of a study is to determine whether there is convergence or not, then it is advisable to calculate the coefficient for several years around the desired ending year. This will permit tracking the beta coefficient over time to see the change in pattern instead of relying on the sign of the slope to declare convergence, divergence, or lack thereof. It would be illadvised to choose particular beginning and ending points and based on the sign (and significance) of the regression coefficient to make a declaration about convergence.

Does this mean that regression analysis cannot or should not be used to examine $\beta$ convergence? After all, there are still $\sigma$-convergence and stochastic convergence to use. Furthermore, there are other measures such as panel analysis or quintile regression. The answer is no. The purpose of this study is not to discredit the method or the researchers that use it. $\beta$ convergence is a mean to empirically examine the neoclassical growth theory. Other convergences serve different purposes and approach the problem differently. At least according to Young, Higgins, and Levy (2007), the presence of $\beta$-convergence does not imply the existence of $\sigma$-convergence. Furthermore, it is not clear how the temporal problem affects panel data or quintile regression. Future research should examine the possibility of similar problems with panel and other data as well as with quintile regression or other suggested corrections such as Markov Chains. Whether these other tools suffer from comparable malaise or other side effects is yet to be determined.

(C) Southern Regional Science Association 2009. 
It is important to avoid comparisons of studies with differing units of observation (e.g. countries versus regions) and of different durations. It would be prudent to be aware of the effect of these two sampling issues in the study of neoclassical growth theory using $\beta$-convergence. It would be interesting to see if researchers develop a temporal econometrics to account for a lack of temporal independence much as the spatial econometrics handles the lack of spatial independence.

\section{REFERENCES}

Amos, Orley M., Jr. (1991) "Divergence of Per Capita Real Gross State Product by Sector1963 to 1986,” Review of Regional Studies, 21, 221-234.

. (1986) “Substate and SMSA Personal Income Inequality and Regional Development," Review of Regional Studies, 16, 23-30.

Anselin, Luc. (1998) Spatial Econometrics: Methods and Models. Kluwer: Boston.

Barro, Robert and Xavier Sala-i-Martin. (2004) Economic Growth, $2^{\text {nd }}$ ed. MIT Press: Cambridge, MA.

. (1992) “Convergence,” Journal of Political Economy, 100, 223-251.

. (1991) “Convergence across States and Regions,” Brooking Papers on Economic Activity, 1, 107-158.

Baumol, William. (1986) "Productivity Growth, Convergence and Welfare," American Economic Review, 76, 1072-1085.

Ben-David, Dan. (1998) “Convergence Clubs and Subsistence Economies,” Journal of Development Economics, 55, 155-171.

Bernard, Andrew B. (1991) Empirical Implications of the Convergence Hypothesis. Center for Economic Policy Research Stanford University: Stanford, California.

Bernat, G. Andrew, Jr. (2001) “Convergence in State per Capita Personal Income, 1950-99,” Survey of Current Business, 81(6), 36-53.

Carlino, Gerald. A. and Leonard Mills. (1996) “Testing Neoclassical Convergence in Regional Incomes and Earnings,” Regional Science \& Urban Economics, 26, 565-590.

David, Florence N. (1938) Tables of the Ordinates and Probability Integral of the Distribution of the Correlation Coefficient in Small Samples. Cambridge University Press: Cambridge, MA.

Eff, Ellis A. (1999) "Myrdal Contra Ohlin: Accounting for the Sources of U.S. County Per Capita Income Convergence Using a Flexible Decomposition Approach,” Review of Regional Studies, 29, 13-36.

Engle, Robert F. and Clive W. J. Granger. (1987) "Cointegration and Error-Correlation: Representation, Estimation and Testing,” Econometrics, 55, 251-276.

Fingleton, Bernard. (1999) "Estimates of Time to Economic Convergence: An Analysis of Regions of the European Union,” International Regional Science Review, 22, 5-34.

(C) Southern Regional Science Association 2009. 
Friedman, Milton. (1992) “Do Old Fallacies Ever Die?,” Journal of Economic Literature, 30, 2129-2132.

Griffith, Daniel A. (2007) Advanced Spatial Statistics. Kluwer Academic Publishers: Boston, Massachusetts.

Hart, Peter E. (1995) "Galtonian Regression across Countries and the Convergence of Productivity,” The Oxford Bulletin of Economics and Statistics, 57, 287-293.

Howitt, Peter. (2000) “Endogenous Growth and Cross-Country Income Differences,” American Economic Review, 90, 829-846.

Hume, David. (1752 [1906]). Political Discourses. Walter Scott Publishing Co., Ltd.: London.

Latzko, David A. (2001). "Industry Mix, Wages, and the Divergence of County Income in Pennsylvania,” Review of Urban and Regional Development Studies, 13, 110-122.

Levernier, William B., Dan S. Rickman, and Mark D. Partridge. (1995) "Variation in U.S. State Income Inequality: 1960-1990,” International Regional Science Review, 18, 355-378.

Levy, Frank and Richard Murnane. (1992) “U.S. Earnings Levels and Earnings Inequality,” Journal of Economic Literature, 30, 1333-1381.

Maxwell, Phillip, and Hite James C. (1992) “The Recent Divergence of Regional Per Capita Incomes: Some Evidence from Australia,” Growth \& Change, 23, 37-54.

Morrill, Richard. (2000) "Geographic Variation in Change in Income Inequality among U.S. State, 1970-1990,” Annals of Regional Science, 34, 109-130.

Myrdal, Gunnar. (1957) Economic Theory and Under-Developed Regions. Gerald Duckworth \& Co., Ltd.: London.

Nissan, Edward and George Carter. (2001) "Income Dispersion between States of Different Regions in the United States, Including Comparisons with Australia,” Australasian Journal of Regional Studies, 7, 151-165.

Ram, Rati. (1992) "Interstate Income Inequality in the United States: Measurement, Modeling and Some Characteristics,” Review of Income and Wealth, 38, 39-48.

Rey, Sergio J. (2001) "Spatial Empirics for Economic Growth and Convergence,” Geographical Analysis, 33, 195-214.

Rowley, Thomas D., John M. Redman, and John Angle. (1991) The Rapid Rise in State Per Capita Income Inequality in the 1980. U.S. Department of Agriculture: Washington, D.C.

Romer, Paul. (1989) “Capital Accumulation in the Theory of Long Run Growth,” In Robert Barro (ed.), Modern Business Cycle Theory. Harvard University Press: Cambridge, MA, pp. 51-127.

Quah, Danny. (1993) “Galton's Fallacy and Tests of the Convergence Hypothesis,” Scandinavian Journal of Economics, 95, 427-443.

Santopietro, George D. (2002) “Analyzing Income Convergence at the County Level: The Case of Development in Central Appalachia,” Journal of Economic Issues, 36, 893-906.

Smith, Adam. (1776 [1937]) An Inquiry into the Nature and Causes of the Wealth of Nations, $5^{\text {th }}$ ed. Modern Library: New York.

(C) Southern Regional Science Association 2009. 
Solow, Robert Merton. (1956) “A Contribution to the Theory of Economic Growth,” Quarterly Journal of Economics, 70, 65-94.

Young, Andrew Thomas, Matthew J. Higgins, and Daniel Levy. (2007) "Sigma Convergence versus Beta Convergence: Evidence from U.S. Country-level Data,” Journal of Money, Credit, and Banking, 40, 1083-1093. 


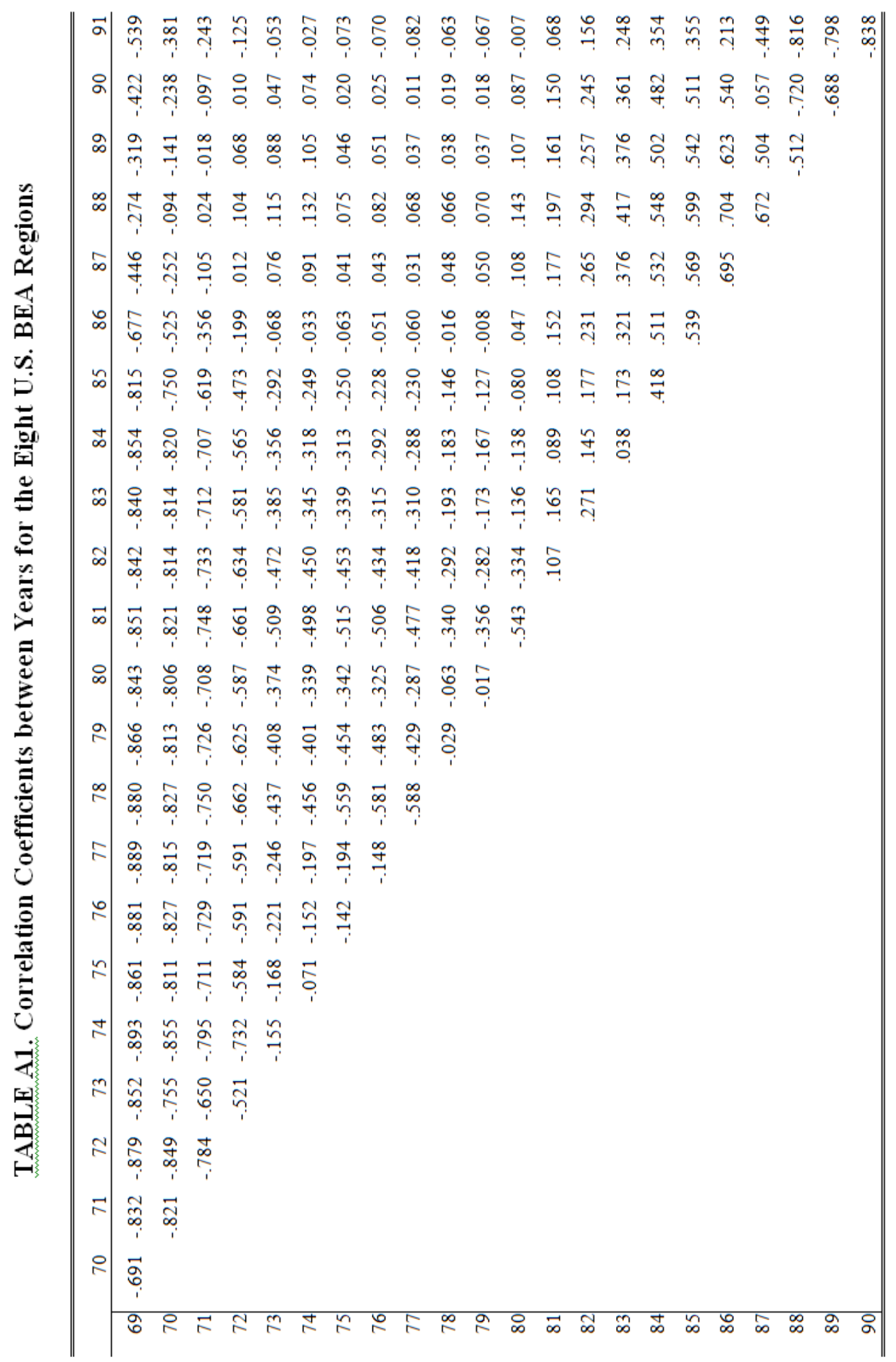

(C) Southern Regional Science Association 2009. 